Notas sobre a constituição da rede de circulação de mercadorias entre o litoral do Rio de Janeiro e os sertões mineiros (1750-1820)

Notes about the formation of the network for the circulation of goods between the coast of Rio de Janeiro and the hinterlands of Minas Gerais (1750-1820) Notes sur la formation du réseau de circulation des marchandises entre le littoral du Rio de Janeiro et l'intérieur du Minas Gerais (1750-1820) Apuntes a respecto de la constitución de la red de circulación de mercancías entre la costa de Río de Janeiro y el interior de Minas Gerais (1750-1820)

\title{
Patrícia Gomes da Silveira
}

\section{(2) OpenEdition}

\section{Journals}

Edição electrónica

URL: https://journals.openedition.org/terrabrasilis/7754

DOI: 10.4000/terrabrasilis. 7754

ISSN: 2316-7793

Editora

Rede Brasileira de História da Geografia e Geografia Histórica

Refêrencia eletrónica

Patrícia Gomes da Silveira, «Notas sobre a constituição da rede de circulação de mercadorias entre o litoral do Rio de Janeiro e os sertões mineiros (1750-1820)», Terra Brasilis [Online], 14 | 2020, posto online no dia 31 dezembro 2020, consultado o 05 dezembro 2022. URL: http:// journals.openedition.org/terrabrasilis/7754 ; DOI: https://doi.org/10.4000/terrabrasilis. 7754

Este documento foi criado de forma automática no dia 5 dezembro 2022.

All rights reserved 


\section{Notas sobre a constituição da rede de circulação de mercadorias entre o litoral do Rio de Janeiro e os sertões mineiros (1750-1820)}

Notes about the formation of the network for the circulation of goods between the coast of Rio de Janeiro and the hinterlands of Minas Gerais (1750-1820) Notes sur la formation du réseau de circulation des marchandises entre le littoral du Rio de Janeiro et l'intérieur du Minas Gerais (1750-1820) Apuntes a respecto de la constitución de la red de circulación de mercancías entre la costa de Río de Janeiro y el interior de Minas Gerais (1750-1820)

\section{Patrícia Gomes da Silveira}

\section{NOTA DO AUTOR}

A pesquisa apresentada abaixo foi desenvolvida no Programa de Pós-Graduação em Geografia da Universidade Federal do Rio de Janeiro (PPGG-UFRJ), entre os anos 2016 a 2020, sob a orientação da Prof ${ }^{a}$. Dra . Gisela Aquino Pires do Rio.

1 O texto aqui apresentado examina, em linhas gerais, o desenvolvimento da pesquisa de doutorado intitulada: $O$ avesso da metrópole: rotas e fluxos de mercadorias entre o litoral e os sertões mineiros, 1750-1820. Antes de explicitar, de forma resumida, a abordagem conferida ao tema, as fontes históricas consultadas e as delimitações temporal e espacial adotadas nesta pesquisa, acreditamos que é importante informar ao leitor que nossas reflexões sobre o tema resultam das investigações e debates travados ao longo do mestrado. Na dissertação A metrópole é aqui: redes de abastecimento e o porto do Rio de Janeiro no comércio de cabotagem, 1799-1822, ${ }^{1}$ discutimos os fatores e processos envolvidos na formação de redes de abastecimento de gêneros alimentícios no início do século XIX 
e privilegiamos a análise das interações que o porto do Rio mantinha com outros portos da América portuguesa pelo comércio de cabotagem. Reconhecemos que determinadas questões foram parcialmente elucidadas, enquanto outras foram ampliadas e são rediscutidas nesta tese, especialmente aquelas que se referem às interações econômicas e às vinculações terrestres e fluviais estabelecidas entre o Rio de Janeiro e os sertões de Minas Gerais.

2 A abordagem utilizada teve como base os métodos e fundamentos da Geografia Histórica, de modo geral pautados na articulação entre Geografia e História. Propomos questões geográficas para o entendimento da ordem espacial em um recorte temporal pretérito. Nosso objetivo central é analisar a constituição de uma rede de circulação de mercadorias no período que se estende entre as décadas de 1750 a 1820, com interesse particular na porção centro-sul da América portuguesa. Conferimos ênfase à circulação de mercadorias estabelecida entre o litoral, aqui representado pela cidade do Rio de Janeiro, e os sertões da capitania de Minas Gerais, a exemplo dos sertões do Leste, da Mantiqueira e da Farinha Podre. ${ }^{2}$

3 À época, definia-se o litoral como espaço conhecido, civilizado e dotado de racionalidade econômica; já o sertão pertencia a outro estágio civilizatório, inferior e primitivo. A ausência de fé, lei e rei era a marca dos sertões e de sua população. Concordamos com Moraes (2002-2003: 14) quando ele reconheceu que o conjunto de valores, geralmente negativos, atribuídos aos sertões “(...) significa, portanto, projetar sua valorização futura em moldes diferentes dos vigentes no momento dessa ação". A denominação sertão não era definida de maneira ingênua e genérica, mas permeada por interesses e atribuída a um espaço-alvo de projetos. Inferimos que, ao exercer tal prática, a Coroa portuguesa e seus funcionários régios reconheciam que por ali havia circulação, produção e demanda - em níveis quantitativos e qualitativos a serem mais bem desvendados, principalmente a partir de pesquisa empírica.

4 Nesse contexto, era necessário e premente implantar um projeto de domínio territorial e político para os espaços interiores da América portuguesa, especificamente àqueles que possuíam grandes riquezas auríferas e diamantíferas, caso da capitania de Minas Gerais. Desta forma, a partir das primeiras décadas do século XVIII, em paralelo ao plano "urbanizador" pautado na fundação de vilas em Minas Gerais, estruturas espaciais de controle da circulação foram instaladas nos sertões auríferos. Pessoas, informações e mercadorias, notadamente pedras preciosas, estavam sujeitas a esse sistema de interditos. Postos fiscais (Registros), guardas militares e presídios pontilhavam a paisagem destes sertões.

5 Recorremos às fontes primárias, as mesmas tradicionalmente utilizadas em trabalhos na História, com o objetivo de questionar a ideia de que sertão e litoral são espaços dicotômicos, sem interação, bem como a do sertão como espaço isolado, primitivo e inferior em relação ao litoral. A fonte primária privilegiada nesta tese consiste nos livros fiscais dos Registros de Entradas e Saídas encontrados na Coleção Casa dos Contos de Ouro Preto (Arquivo Nacional - RJ). ${ }^{3}$ Nos Registros eram cobradas taxas sobre as mercadorias que entravam ou saíam de Minas Gerais. A partir da organização dos dados coletados nesta fonte será possível analisar a rede de abastecimento de mercadorias que se desenhou na porção centro-sul da América portuguesa, apoiada em uma estrutura que envolvia uma rede de trilhas e caminhos, lugares (pousos, arraiais, vilas) e comerciantes (tropeiros, boiadeiros, condutores). 
6 Uma série de procedimentos precisa ser adotada ao lidar com a pesquisa documental. É essencial se familiarizar com as normas e métodos de organização e classificação dos documentos adotados pela instituição arquivística na qual será realizada a pesquisa. Conhecer as condições de produção da fonte selecionada, assim como sua estrutura, conteúdo e estado de preservação, também é crucial. Nas primeiras visitas que fizemos ao Arquivo Nacional (RJ), a partir de 2017, este foi nosso intuito.

7 Após conhecer um pouco mais sobre a fonte selecionada, começamos nosso levantamento. Percebemos também que era preciso entender mais sobre topônimos, abreviações, tipos de unidades de medida, nomes de produtos, que comumente apareciam nas envelhecidas páginas destes livros.

8 As lacunas temporais e o caráter fragmentário dessa fonte representaram um desafio à pesquisa, além das dificuldades de leitura inerentes a este tipo de material. Como são manuscritos do século XVIII, a letra cursiva empregada, repleta de ligaduras e inclinações, dificultou em certos momentos o entendimento completo do texto. Além disso, alguns códices possuem folhas rasgadas e manchadas, resultado da ação natural do tempo ou mesmo do tipo de tinta utilizada à época, que pode dar origem a borrões que danificam o documento. Também lembramos que, se em outras disciplinas é comum o trabalho com documentação arquivística, na Geografia isso soa pouco familiar, o que não é um impedimento, mas exige significativo investimento de tempo, paciência e leitura para lidar com o "trabalho de campo" em arquivos e bibliotecas.

9 Apesar das dificuldades expostas anteriormente, essa fonte oferece um rico conjunto de dados que nos permite analisar a circulação de mercadorias entre o litoral da cidade do Rio e os sertões mineiros. Além dos livros fiscais dos Registros, também consultamos outras fontes primárias - mapas históricos, correspondências dos administradores dos Registros - e secundárias. Com base nos dados e informações catalogados a partir de tais fontes, produzimos mapas temáticos com o auxílio das ferramentas dos Sistemas de Informação Geográfica (SIG). Ressaltamos que os mapas foram elaborados a partir dos objetivos propostos nesta pesquisa e são resultado de nosso "trabalho de campo" nos arquivos.

10 Sublinhamos que a disponibilidade dos dados na fonte selecionada também contribuiu para a delimitação do período da análise (1750-1820). A partir de 1830, houve uma reorganização tributária em Minas Gerais - criação de novos impostos, mudanças na localização e função dos Registros -, de modo que essa fonte deixou de ser publicada em 1832.

11 O recorte temporal adotado também se justifica pelos arranjos econômicos, políticos e territoriais contemporâneos verificados na capitania de Minas Gerais. Esse período foi marcado pelo declínio da produção aurífera e pela progressiva reestruturação produtiva pautada em atividades agropecuárias, comerciais e artesanais. Outro ponto importante refere-se às mudanças significativas na escala e orientação dos fluxos de mercadorias entre o litoral e o sertão. A partir da abertura e consolidação da rota do Caminho Novo, a cidade do Rio adquiriu certa centralidade no abastecimento da capitania mineira. Aberta nos idos de 1700, essa rota reduzia de forma considerável o deslocamento entre o litoral carioca e os sertões auríferos de Minas Gerais. Aliados a essa agilidade nas comunicações, fatores de ordem política também colaboraram para a escolha dessa rota como a oficial, tanto no acesso a Minas como no escoamento do ouro via porto do Rio para Portugal. 

(1763) consolidou o papel desta cidade como um dos principais entrepostos comerciais do território colonial, dando-se ênfase às suas articulações mercantis com localidades da porção centro-sul. Além disso, as distintas redes de comércio nas quais a cidade estava inserida reforçaram sua importância no Atlântico Sul, especialmente no que tange ao tráfico de escravos africanos.

13

Esse quadro adquiriu novos conteúdos, arranjos e personagens quando, em 1808, a Família Real portuguesa se instalou no Rio de Janeiro, de modo que “(...) a cidade se metamorfosearia em Corte e capital da monarquia e do Império português, redimensionando os elementos e o significado de sua capitalidade" (Bicalho, 2006: 20). Nesse contexto, destacava-se uma considerável pauta de exportações de Minas Gerais, em termo de quantidade e diversidade de gêneros, em direção à cidade do Rio de Janeiro, cujo mercado se ampliou com a instalação da Corte na cidade.

14 Uma nova fase se inaugurava no Rio de Janeiro marcada pelo incremento em sua população, que passou de aproximadamente 40 mil habitantes, em 1799, para 60 mil, em 1808, e 90 mil em 1819; recebimento de uma série de melhoramentos urbanos; e implementação de instituições artístico-culturais (Fragoso e Florentino, 1993). Para a Coroa também era essencial garantir a integração entre as capitanias e, com esse objetivo, foram abertas novas estradas, que ligavam especialmente o litoral do Rio de Janeiro à porção sul de Minas Gerais, como as Estradas do Comércio e da Polícia importantes vetores de ocupação populacional e econômica do Vale do Paraíba nos Oitocentos.

Pretendemos mostrar neste trabalho as interações do litoral com os sertões de Minas Gerais a partir da circulação de mercadorias, descortinando a dinâmica que existia nos sertões e como estes não eram espaços vazios, isolados e desconhecidos. A circulação de mercadorias evidenciada pelos dados dos Registros é um dos indícios que contradiz este conjunto de valores negativos comum e caricaturalmente aplicados aos sertões coloniais.

16 Apesar da polarização e dos antagonismos que classificavam os sertões no período em tela, verificou-se a formação de importantes redes de comércio. A demanda existente nos sertões mineiros, representada pela população aí fixada, exigia regularidade no abastecimento, o que seria viabilizado pelas rotas que articulavam litoral e sertão, conforme indicam as trilhas e caminhos do período. 0 amplo conjunto de "homens e mulheres de caminho" que as percorriam carregando uma série de mercadorias também corroboram a existência de trocas regulares, não apenas para atender a demanda local, ou seja, da população fixada nos diversos povoados de Minas, mas também a Atlântica, com a exportação, sobretudo pelo porto do Rio, de tabaco, carne, couro, entre outros gêneros produzidos em Minas Gerais.

O nosso mergulho nos arquivos e o uso de fontes primárias nos proporcionaram conhecer "territórios" ainda pouco explorados pelos geógrafos. Examinamos bastante essa discussão na tese e acreditamos que ela pode ser entendida como uma contribuição metodológica do trabalho, mas também um convite a adentrar em certos "sertões incógnitos" da prática geográfica. 


\section{BIBLIOGRAFIA}

Bicalho, Maria Fernanda (2006). “O Rio de Janeiro no século XVIII: A transferência da capital e a construção do território centro-sul da América portuguesa”. URBANA: Revista Eletrônica do Centro Interdisciplinar de Estudos sobre a Cidade, v. 1, n. 1, pp. 1-20.

Fragoso, João Luis Ribeiro; Florentino, Manolo (1993). O arcaísmo como projeto: mercado atlântico, sociedade agrária e elite mercantil no Rio de Janeiro, c. 1790-c. 1840. Rio de Janeiro: Diadorim.

Moraes, Antonio Carlos Robert (2002-2003). “O Sertão: um “outro” geográfico”. Terra Brasilis, n. 4-5. Disponível em: http://journals.openedition.org/terrabrasilis/341 Acesso em: 10 set. 2020.

\section{NOTAS}

1. Dissertação defendida em 2013, sob orientação da Prof ${ }^{a}$. Dra ${ }^{a}$. Gisela Aquino Pires do Rio, no PPGG-UFRJ. Trabalhamos com os Códices de Embarcações que retratam o comércio de cabotagem entre 1795-1831 e estão disponíveis à consulta no Arquivo Geral da Cidade do Rio de Janeiro (AGCRJ).

2. Empregamos o termo capitania para fazer referência às antigas unidades territoriais do Brasil colônia.

3. Consultamos os livros fiscais (códices) dos Registros de Entradas/Saídas da Coleção Casa dos Contos de Ouro Preto (Arquivo Nacional-RJ). Diariamente, os funcionários dos Registros anotavam nestes livros: a data da passagem; o nome do condutor responsável pelas mercadorias; tipo e quantidade das mercadorias (secos, molhados, gado, escravos, sal etc.); origem e destino das mesmas (em alguns casos); e o imposto a ser pago. Os Registros eram instalados nos limites da capitania de Minas Gerais ou no seu interior, geralmente em lugares estratégicos, como margem de rios, ao longo das Estradas Reais do Ouro ou no entroncamento de caminhos e picadas.

\section{RESUMOS}

Esta nota de pesquisa visa apresentar o desenvolvimento da pesquisa de doutorado " $O$ avesso da metrópole: rotas e fluxos de mercadorias entre o litoral e os sertões mineiros, 1750-1820". Construída na perspectiva da Geografia Histórica, o objetivo central da pesquisa consiste em analisar a constituição de uma rede de circulação de mercadorias no "presente de então" a partir das interações do litoral com os sertões de Minas Gerais. Dentre as principais fontes históricas pesquisadas, destacamos documentação estatística, mapas históricos, correspondências e censos populacionais do período em tela.

This research note aims to present the development of the doctoral research "The reverse of the metropolis: routes and flows of goods between the coast and the hinterlands of Minas Gerais, 1750-1820". Built in the perspective of Historical Geography, the goal of this research is to analyze the constitution of a network of circulation of goods in the "presente de então" from the interactions between the coast and the backlands of Minas Gerais. Among the main historical sources 
researched, we highlight statistical documentation, historical maps, correspondences and population censuses of the period in question.

Cette note de recherche vise à présenter le développement de la recherche doctorale "Le revers de la métropole: routes et flux de marchandises entre la côte et l'intérieur du Minas Gerais, 1750-1820". Construit dans la perspective de la Géographie Historique, l' objectif de cette recherche est d'analyser la constitution d'un réseau de circulation des marchandises dans le "presente de então" à partir des interactions entre la côte et l'intérieur du Minas Gerais. Parmi les principales sources historiques recherchées, nous mettons en évidence la documentation statistique, les cartes anciennes, les correspondances et les recensements de la population dans le période considérée.

Esta nota de investigación tiene como objetivo presentar el desarrollo de la investigación doctoral "El reverso de la metrópoli: rutas y flujos de mercancías entre la costa y el interior de Minas Gerais, 1750-1820". Construido desde la perspectiva de la Geografía Histórica, el objetivo central de la investigación es analizar la constitución de una red de circulación de bienes en el "presente de então" a partir de las interacciones entre la costa y el interior de Minas Gerais. Entre las principales fuentes históricas investigadas, destacamos documentación estadística, mapas históricos, correspondencias y censos de población del período en cuestión.

\section{ÍNDICE}

Índice geográfico: Rio de Janeiro, Minas Gerais

Mots-clés: sources historiques, géographie historique, circulation, réseaux, Amérique

Portugaise

Índice cronológico: $1750-1820$

Palavras-chave: fontes históricas, geografia histórica, circulação, redes, América portuguesa Keywords: historical sources, historical geography, circulation, networks, Portuguese empire Palabras claves: fuentes históricas, geografía histórica, circulación, redes, América portuguesa

\section{AUTOR}

\section{PATRÍCIA GOMES DA SILVEIRA}

Professora do Departamento de Geografia do Colégio Pedro II.

Doutoranda do Programa de Pós-Graduação em Geografia da Universidade Federal do Rio de Janeiro (PPGG-UFRJ).

silveirag.patricia@gmail.com 